\title{
Staff perceptions of implementing health coaching as a tool for self management in chronic disease: A qualitative study
}

\author{
Kaye Ervin, Vivienne J effery \\ University of Melbourne, Victoria, Australia \\ Correspondence: Kaye Ervin. Address: University of Melbourne, Cobram, Victoria, Australia. \\ Email: ervink@humehealth.org.au. \\ Received: February 21, 2012 \\ Accepted: May 6, 2013 \\ Online Published: J une 26, 2013 \\ DOI : 10.5430/jnep.v3n9p131 \\ URL: http://dx.doi.org/10.5430/jnep.v3n9p131
}

\begin{abstract}
Introduction: Self management in chronic disease is the cornerstone of the Australian National Primary Health Care Strategy, with funding widely available to health services to facilitate staff training in self management strategies for clients. Changing care delivery models in management of chronic disease post training has proven difficult for staff.

Method: Semi structured interviews were conducted with consenting staff who had been trained in client self management strategies, to explore barriers and enablers to implementing their training into practice in the primary care setting.

Results: Staff recognise the value of client self management in chronic disease and perceive it as wholly relevant to their role, but identify many barriers to implementing it into practice. Confidence or self efficacy of staff in implementing the training into practice is repeatedly cited as a barrier.

Discussion: Health care organisations should review their processes and infra structure to allow self management strategies to be easily incorporated into routine work practices and models of care delivery. Identifying and supporting staff who report low self efficacy or confidence is essential to facilitating self management strategies in chronic disease.
\end{abstract}

\section{Key words}

Chronic disease, Self management, Health coaching, Training implementation

\section{I ntroduction}

Self management is becoming recognised as a vital aspect to help manage chronic disease, with Australian public health policy now having self management as an intervention ${ }^{[1,2]}$. Despite this, researchers in Australia have recently found that there is little consensus among primary health care workers of what constitutes self management ${ }^{[3]}$ and there are further recommendations of the need to elucidate which components of a self-management program are and are not effective. Research regarding staff opinions and perceptions of self management as an effective tool in managing chronic disease is slowly emerging in the Australian setting ${ }^{[2-5]}$.

The current literature emphasises that the skill and attitude of the primary health care clinician is essential to effective self management for clients ${ }^{[6,7]}$. 
There are many models of self management in chronic disease, with staff training available which endeavours to assist the implementation of the model in practice. A commonly used model in Australia is health coaching.

Health coaching is a collection of evidence-based interventions and techniques from various applications of psychology that assist health professionals to work with patients to change their behavior ${ }^{[8]}$. It is employed by health professionals to enhance the wellbeing of individuals and to facilitate the achievement of their health-related goals ${ }^{[9]}$.

Effective health coaching engages the patient as a partner in self management, rather than being a passive recipient of care ${ }^{[10]}$. The benefits of this approach are multi factorial, including better compliance, greater continuity of care, improvements in health status and reduced hospital admissions ${ }^{[11]}$.

Translation of staff training in client self management of chronic disease into practice has been identified as a major problem in Australia and overseas ${ }^{[12,13]}$. This project aimed to elicit the perceptions of primary health care staff of implementing self management, using health coaching as a framework model, for clients with chronic disease.

Staff from four small health services and one home and community care (HACC) agency, located in rural Victoria, Australia, undertook health coaching training. The purpose of the training was to facilitate effective models of self management for clients with chronic disease. Following the training, the implementation of the health coaching skills for self management of chronic disease was evaluated. This paper reports the findings of the qualitative arm of a broader study.

\section{Ethical approval}

Ethical approval for the project was granted by Goulburn Valley Health Research and Ethics Committee and conducted in compliance with the NHMRC guidelines on ethical conduct in Human Research.

\section{Methodology}

A total of 46 primary health care staff, from five different organisations, undertook Health Coaching (HC) training. The training places were allocated in relation to the amount of effective full time positions per organisation working with clients with chronic disease. The study utilised a mixed methodology for evaluation.

The methodology is comprehensively described in the quantitative findings ${ }^{[2]}$ but briefly, staff were surveyed with provision of reply paid envelope. The project manager identified staff members who had undertaken HC training, and distributed surveys via managers at each site. The survey tool elicited information relating to perceived barriers and enablers to converting health coaching training into clinical practice. There were 30 respondents to the survey (68\%) and the findings from this quantitative arm of the study have been previously published ${ }^{[2]}$.

At the end of the survey, participating staff were asked to further participate by volunteering to undertake a semi structured interview, which is the subject of this paper. The qualitative findings are reported using the COREQ - a 32 item criteria for reporting qualitative studies ${ }^{[14]}$.

\subsection{I nterviews}

An independent research academic conducted the staff interviews. The interviewer is also a registered nurse who had a good understanding of the concepts and issues described by the interview participants. The interviewer is female and has previous qualitative project experience.

The interviewer had no pre existing relationship with the interview participants, and had no stake in the outcome of the project or findings of the interviews. 
The theoretical underpinnings of the study were grounded in phenomenology, in that the researchers were interested in the individual staff perspectives. It was a purposive sampling method, only staff who had undertaken the HC training were invited to be interviewed. The invitation was extended to staff who completed the quantitative survey, those who consented were required to complete contact details for follow up. Fifteen respondents consented to be interviewed (50\%), with a final 10 available to take part during the period of time the interviews were conducted. Reasons were not sought for non participation.

The interviews were conducted at the respondents preferred location (usually workplaces) and recorded for transcription. Only the interviewer and interviewee were present at the time of the interview. Most of the interviews were of approximately 20 minutes duration. The interview schedule consisted of 11 questions, including staff opinions about the training undertaken, their perception as to whether training was expected to be implemented and whether it was relevant to their role, barriers to implementation of training and the additional client time allowance for implementation. Questions also included how staff decided who to use health coaching with, the use of health coaching templates, what organisational changes would facilitate implementation of health coaching in the workplace, staff perceptions of readiness, importance and confidence to implement health coaching, whether colleague support was utilised, and finally general perceptions about health coaching and its implementation.

\subsection{Participant group}

Demographic information about the study participants is described in detail in the quantitative paper ${ }^{[2]}$. To add clarity, the interview participants are also briefly described here. There was a wide age range of 24-61 years, with the average age of participants 44 years. Years of service ranged from 1-35 years, averaging 13.4 years. The positions held also varied, but the majority were community health nurses. The remaining interview participants worked in allied health fields such as physiotherapy or dietetics. Respondents were evenly spread across the five services, with two staff from each site participating in an interview. All of the interview participants indicated that they had implemented (or had attempted to implement) at least some of the principles of HC training in practice.

\subsection{Analysis}

A collaborative thematic analysis was conducted on the transcribed interviews. Due to the small number of interviews, no computer software was used to manage or analyse the data. Two researchers read the transcripts and identified key words. The key words were assigned to overall themes that the researchers identified and discussed from the transcripts.

Participants were not asked to provide feedback on the findings. Due to the small number of participants quotations are not identified in order to preserve confidentiality, but there is good representation across the group.

\section{Findings}

\subsection{Self management as a change in the model of care}

The staff perceptions of health coaching as a tool to assist self management in chronic disease was overwhelmingly positive. Participants commented on the depth and value of the training and without exception perceived it to be a useful method of facilitating change. It was perceived as being very different to their usual practice, which is described by the following participant;

"I have never done anything like that before and I think it's quite an eye opener, because in the past I am very used to telling the patients what to do and then expecting them to go away and do it, and quite often I find that doesn't really work. Often they will come back and I will ask them, 'oh have you had a go doing this?' Then they 
are 'oh yeah maybe' or 'a little bit' 'not as much', and you can really tell they haven't done it, because they are not really interested in doing it."

And,

"I guess it's different from the old way, where clinicians would tell the client what to do instead of them starting to take some responsibility for their illness."

\subsection{Health coaching is relevant to primary health care}

All of the participants reported that Health Coaching was relevant to their role in primary health care. Helping the clients to set their own goals and not having the clinician determine and enforce goals as part of their care was recognized as an important part of gaining cooperation and compliance with health care regimes. One participant responded that:

"I think it is relevant, I definitely think its relevant to our role, because I think if someone comes in to see you then you know what the best outcome for them is. I think they've got to play an interactive role in whatever plan you've got, like it is no use you setting out goals that are totally unachievable."

None of the participants reported that Health Coaching was not relevant to their role. Some participants viewed it as an extension to their practice or as enhancing the former model of care they used:

"Oh look, it was a little bit different but it was probably better, like I set goals before but not in the same way that health coaching does. It sort of goes about it better."

\subsection{Multifactorial barriers and enablers to implementing self management}

Individual participants identified multiple barriers to the implementation of health coaching into their usual work practices. There was little consensus that one factor alone contributed to them being unable to implement health coaching, yet the quantitative arm of the study identified time as the predominant barrier to implementation ${ }^{[2]}$. Participants reported client's intellectual capacity, age and motivation as well as their own level of experience, organizational support and effectiveness as barriers to implementing health coaching. One participant described;

“I feel a little bit disappointed. I try sometimes and it doesn't work, so I think, 'oh what did I do wrong?' I use the work sheet off the internet. I've gone on there and printed off a few of those to start off with, mostly the goal hierarchy and the goals action plan and a few other things, a few other tools. So yeah I tried them, but the thing is, I think because I have a diverse role and like the people I see, everyone is so different, and it's not always clear cut to what tools to use."

Because the quantitative results identified time as a barrier to implementing self management techniques for clients, each health service allocated staff members more time with clients in an attempt to embed health coaching principles. Participants interviewed reported that the extra allocation of time was not helpful for a variety of reasons. One participant reported that her workload was so heavy that spending extra time with clients would simply blow out the waiting list, while others reported that time was only one of the factors and so not necessarily the overall solution to implementing health coaching.

"There was extra time allowance but being the sole practitioner it just doesn't work out that way. You still have the same amount of people to see in that same small time frame, um, you've got to make it fit. Then that would have blown out in terms of waiting lists and what not for the service, so that was tricky." 
Support from peers and from the organization the staff member worked for, was perceived as being important to the implementation of the health coaching skills. Working in an environment where staff could discuss what did or didn't work was an important part of embedding the skills learnt. Primary health care staff who worked in small organizations where few other staff had undertaken the HC training felt particularly isolated, but also identified that leaving their workplace to discuss the training with other trained staff in other health service organizations was also problematic.

"I think every client who comes through the door should have some form of health coaching, but that's not possible in a small hospital. Other staff don't know what I'm doing, where other places they have each other for support. We have regathering days but I can't always get there because I have too many clients to see."

Staff who did have support reported this very favourably:

"I have talked to colleagues about it, especially XXX who actually did the course with me, and um, she uses it quite a lot in district nursing, so um, yes we do talk about and it and it is helpful to bounce off someone else. Yeah.”

\subsection{Having confidence in implementing self management with clients}

Health Coaching training discusses clients confidence in self management as a necessary construct for positive progress. HC can use numerical scaling to quantify confidence. A client's confidence is considered low if they nominate a number below seven out of ten regarding their ability to self manage their illness ${ }^{[8]}$. Interview participants therefore frequently spoke about their own confidence in a numerical context. The participants reported that their own level of confidence was below seven out of ten, meaning that they did not feel they had the confidence to implement the health coaching training into practice.

"I wasn't confident because I hadn't done it before and I think it is just a matter of practice and getting familiar with the language and to peoples reaction to it. About a five, I was very low in confidence."

\section{Discussion}

The findings presented here affirm that effective self management in chronic disease relies largely on the skill and attitudes of clinicians to facilitate it. Despite undertaking training in health coaching and having a positive perception of it as a useful tool to facilitate self management, most of the participants in this study struggled to implement it in practice.

Participants reported that changing their practice to incorporate self management principles was difficult. It is recognized in the literature that changes in the delivery of care are difficult for staff to integrate ${ }^{[13,15]}$. The historical and traditional expectation of a didactic, information giving consultation in primary care, versus the principles of self management is a challenge to alter from both the recipient and provider perspective. Adopting new interactive methods, such as those employed in the health coaching model of care can be difficult and requires the development of new client/practitioner interactions. Many authors ${ }^{[7,16,17]}$ recognise the need for educational activities and training in self management at undergraduate level for health professionals. Learning the skills required to facilitate client self management, at an undergraduate level would at least negate the difficulty associated with changing models of care. Much of the difficulty in implementing the training seemed to stem from the required change in clinician practice. This would be ameliorated by learning the principles as an undergraduate.

The interview participants in this study reported that self management principles were wholly relevant to their role, and they could understand the benefits of clients setting their own achievable goals while being supported by health professionals. Despite this, the participants were slow to embrace the health coaching model in practice, which supports findings from other studies ${ }^{[18]}$. 
The fact that the majority of interview participants experienced difficulty with implementation, suggests that barriers, other than staff attitudes existed. Participants reported many and varied barriers and enablers to implementing the health coaching training. This supports previous findings that a clinicians ability to implement self management skills is shaped by a range of contextual factors ${ }^{[19]}$. The quantitative findings from this study suggest that the context of rurality, both in terms of professional isolation and workload were compounding factors in the lack of implementation ${ }^{[2]}$. Some of the interview participants also allude to this, both in discussion on release time and waiting lists and staff support, which is supported by a previous study ${ }^{[20]}$.

Organisational support was perceived as essential to implementing the new skills. There is evidence in the literature that colleague, management and organisational support is reported to be a significant predictor of successful transfer of training into practice ${ }^{[21,22]}$.

Training providers promote health coaching as a brief intervention which is easily incorporated into existing structures ${ }^{\text {[23] }}$. This view was not shared by the participants in this study, who perceived it to be difficult to integrate into the existing model. Conversely, other authors ${ }^{[24]}$ cite a lack of time as a significant challenge for practitioners to encourage client lifestyle interventions into routine practice, which supports the findings from this study. Participants reported that even increased time allowances for consultations did not ameliorate this burden, as extending consultation times was not possible, given their work load.

Of concern is the participants reported low levels of confidence in facilitating self management techniques. Despite two days of training in this model of care, staff were not confident in utilization of the principles in day to day practice. This is possibly a reflection of the magnitude of change required compared to their previous practice, which some participants articulated. A previous study found that the ability of health care professionals to engage in effective communication during a consultation can reinforce or discourage health actions that maximise a person's capacity to live positively with a chronic condition ${ }^{[25]}$. Furthermore self-confidence of clinicians is reported as essential in promoting health change behaviours for clients with chronic disease ${ }^{[26]}$. Clinician confidence, and perceived self-efficacy, is reported to be a predictive indicator in successful practice change behavior following training ${ }^{[27,28]}$.

A clinicians ability to implement their training into practice, which is the aim of the training, can be simply predicted by measuring their perceived confidence or self-efficacy. This is an important finding for organizations investing time in staff training. Staff who rate their confidence as low will require extra support to facilitate the desired practice change. Former research suggests addressing mechanisms that make health coaching successful and ultimately facilitate its integration into routine health care through a wide range of health professional groups ${ }^{[29]}$.

\section{Limitations}

The low consent rate for further information to barriers and enablers through participant interviews was a limitation to the study. Although $68 \%$ of staff responded to the initial survey, only $21 \%$ of the overall staff trained in health coaching participated in an interview. In addition it can be assumed that those who consented to be interviewed were staff who viewed the training positively. Overall staff perceptions may, in fact, be even more negative than those portrayed.

This small study was a local evaluation of staff training and implementation in a rural setting, which in no way was intended to be generalisable to other settings. Readers may, however find the staff perceptions beneficial if considering similar training in their own health settings.

\section{Conclusion}

Self-management has been the cornerstone of the Australian Government's First National Primary Health Care Strategy $^{[30]}$. 
To improve integration, client self-management support for staff needs to be incorporated as an integral aspect of health service redesign in terms of infrastructure and systems to ensure appropriate uptake and utilisation by key stakeholders. Without this, self-management support will remain on the periphery ${ }^{[31]}$.

\section{Conflicts of interest}

The authors declare no conflicts of interest.

\section{References}

[1] Australian Government Dept of Health and Ageing, National Chronic Disease Strategy. National Health Priority Action Council (NHPAC). 2006. Canberra.

[2] Ervin, K., Jeffery, V., Koschel, A. Evaluating the implementation of health coaching in a rural setting. Journal of Hospital Administration. 2012; 1(2). http://dx.doi.org/10.5430/jha.v1n2p17

[3] Oliveira, V.C., Ferreira, P. H., Maher, C. G., Pinto, R. Z., Refshauge, K. M. and Ferreira, M. L. , Effectiveness of self-management of low back pain: Systematic review with meta-analysis. Arthritis Care and Research. 2012; 64: 1739-1748. PMid:22623349 http://dx.doi.org/10.1002/acr.21737

[4] Stone, G., and Packer, T., Evaluation of a rural chronic disease self management program. International Electronic Journal of Rural and Remote Health. 2010; 10(1203).

[5] Cope, K. Perceptions of Chronic Disease Self Management in rural primary health care and implications for routine clinical practice: a mixed methods study. Clinical education and training Institute, 2012. NSW Government.

[6] Jordan, J., Osborne, R. Chronic disease self-management education programs: Challenges ahead. Medical Journal of Australia. 2007; 186(2): 84-87. PMid:17223770

[7] Hickman, L., Rolley, J. Davidson, P. Can principles of the chronic care model be used to improve care of the older person in the acute care sector? Collegian. 2010; 17: 63-69. PMid:20738058 http://dx.doi.org/10.1016/j.colegn.2010.05.004

[8] Gale, J., \& Lindner, H. The Health Coaching Australia (HCA) Model of Health Coaching for Chronic Condition Self-management (CCSM). Health Coaching Australia, 2007. Available from: www.healthchangeaustralia.com/LiteratureRetrieve.

[9] Palmer, S., Tubbs, I., Whybrow, A. Health coaching to facilitate the promotion of healthy behaviour and achievement of health-related goals. International Journal of Health Promotion and Education. 2003; 41(3): 91-93.

[10] Bodenheimer, T., Lorig, K., Holman, H., Grumbach, K. Patient self-management of chronic disease in primary care. Journal of American Medical Association. 2002; 288(19): 2469-2473. PMid:12435261 http://dx.doi.org/10.1001/jama.288.19.2469

[11] Weeramanthri, T., Hendry, S., Connors, C., Ashbridge, D., Rae, C., Dunn, M., et al. The Northern Territory preventable chronic disease strategy - promoting an integrated and life course approach to chronic disease in Australia. Australian Health Review. 2003; 26(3): 31-42. PMid:15368818 http://dx.doi.org/10.1071/AH030031

[12] Australian Government Department of Health and Ageing, The Primary Health Care Workforce Project: Key findings from consultative activities. Australian Better Health Initiative: A joint Australian, State and Territory government initiative. Capabilities for Supporting Prevention and Chronic Condition Self-Management: A Resource for Educators of Primary Health Care Professionals, 2009.

[13] Glasgow, R., Lichtenstein, E., and Marcus, A., Why Don’t We See More Translation of Health Promotion Research to Practice? Rethinking the Efficacy-to-Effectiveness Transition. American Journal of Public Health. 2003; 93(8). PMid:12893608 http://dx.doi.org/10.2105/AJPH.93.8.1261

[14] Tong, A., Sainsbury, P., Craig, J. Consolidated criteria for reporting qualitative research (COREQ): a 32-item checklist for interviews and focus groups. International Journal for Quality in Health Care. 2007; 19(6): 349-357. PMid:17872937 http://dx.doi.org/10.1093/intqhc/mzm042

[15] Potempa, K., Butterworth, S., Flaherty-Robb, M., Gaynor, W. The healthy ageing model: Health behaviour change for older adults. Collegian. 2010; 17: 51-55. PMid:20738056 http://dx.doi.org/10.1016/j.colegn.2010.04.008

[16] Lawn, S. Top tips for embedding chronic condition self-management support into practice. Australian Journal of Primary Health. 2010; 16: 334-343. PMid:21138702 http://dx.doi.org/10.1071/PY09070

[17] Glasgow, N., Jeon, Y., Kraus, S., Pearce-Brown, C. Chronic disease self-management support: The way forward for Australia. Medical Journal of Australia. 2008; 10 Suppl: S14-S16.

[18] Weeks, A., McAvoy, B., Peterson, B., Furler, J., Walker, C., Swerissen, H., Belfrage, J. Negotiating ownership of chronic illness: An appropriate role for health professionals in chronic illness self-management programs. Australian Journal of Primary Health. 2003; 9(2\&3): 17-20.

Published by Sciedu Press 
[19] Laws, R., Kemp, L., Harris, M., Davies, G., Williams, A., and Eames-Brown, R. An exploration of how clinician attitudes and beliefs influence the implementation of lifestyle risk factor management in primary healthcare: a grounded theory study. Bio Med Central: Implementation Science. 2009; 4(66). PMid:19825189

[20] Mills, J., Intellectual isolation, geographical isolation and information overload of academics at a rural university: an informationseeking perspective. Rural Society. 2004; 12(3).

[21] Machin, A., and Treloar, C. Predictors of motivation to learn when training is mandatory. In 39th Annual Psychological Society Annual Conference. 2004, 29th Sept - 03 Oct. 2004. Sydney, Australia.

[22] Broad, L., and Newstrom, W. Transfer of Training. 1992, New York: Addison-Wesley.

[23] Butterworth, S., Linden, A., McClay, W. Health coaching as an intervention in health management programs. Disease Management Health Outcomes. 2007; 15(5): 315-322. http://dx.doi.org/10.2165/00115677-200715050-00004

[24] Brotons, C., Bjorkelund, C., Bulc, M., Ciurana, R., Godycki-Cwirko, M., Jurgova, E., et al. Prevention and health promotion in clinical practice: the views of general practitioners in Europe. Preventative Medicine. 2005; 40: 595-601. PMid:15749144 http://dx.doi.org/10.1016/j.ypmed.2004.07.020

[25] Thorne, S., Harris, S., Mahoney, K, et al. The context of health care communication in chronic illness. Patient Education and Counselling. 2004; 54: 299-306. PMid:15324981 http://dx.doi.org/10.1016/j.pec.2003.11.009

[26] Burke, L., and Fair, J. Promoting Prevention Skill Sets and Attributes of Health Care Providers Who Deliver Behavioral Interventions. Journal of Cardiovascular Nursing. 2003; 18(4): 256-266. PMid:14518601

[27] Lorenz, R., Gregory, R., and Davis, D. Utility of a Brief Self-Efficacy Scale in Clinical Training Program Evaluation. Evaluation \& the Health Professions. 2000; 23(182). PMid:10947524

[28] Chiaburu, D., and Lindsay, D. Perspectives on Research. Can do or will do? The importance of self-efficacy and instrumentality for training transfer. Human Resource Development International. 2008; 11(2): 199-206. http://dx.doi.org/10.1080/13678860801933004

[29] Lindner, H., Menzies, D., Kelly, J., Taylor, S., Shearer, M. Coaching for behaviour change in chronic disease: A review of the literature and implications for coaching and self management intervention. Australian Journal of Primary Health. 2003; 9(2\&3): $1-9$.

[30] Australian Government Department of Health and Ageing. Primary health care reform in Australia: report to support Australia's First National Primary Health Care Strategy. 2009.

[31] Jordan, J., Briggs, A., Brand, C., Osborne, R. Enhancing patient engagement in chronic disease self-managment support initiatives in Australia: The need for an integrated approach. Medical Journal of Australia. 2008; 189(10 Suppl): S9-S13. 